\title{
Ensino para jovens em áreas vulneráveis
}

\author{
MARIA AMÁBILE MANSUTTI \\ Liliane Petris*
}

O PAE - Programa de Aumento da Escolaridade ${ }^{1}$ consiste na oferta de curso de complementação da escolaridade de ensino fundamental, direcionado para populações beneficiadas pelo Programa de Urbanização de Assentamentos Populares do Rio de Janeiro - PROAP II. Abrangeu 53 comunidades, localizadas nas zonas Sul e Norte da cidade do Rio de Janeiro, caracterizadas como regiões com altos índices de violência social.

A execução do Programa esteve a cargo das secretarias municipais de Assistência Social e da Educação do Rio de Janeiro, em parceria com organizações da sociedade civil - Amebras - Associação de Mulheres Empresárias do Brasil, Cieds - Centro Integrado de Estudos e Programas de Desenvolvimento Sustentável, DC Brasil, Viva Rio - e com o CenPEC - Centro de Estudos e Pesquisas em Educação, Cultura e Ação Comunitária, que teve a função de monitorar e avaliar seu desenvolvimento.

Em sua concepção original, o PAE caracterizava-se como um programa multissetorial, que incluía educação e proteção social. Apostava-se numa ação que visava ao aumento da escolaridade e ao desenvolvimento de condições favoráveis para a inserção do jovem no mundo do trabalho, da cultura, das relações sociais, e sua maior inclusão na vida das comunidades e da cidade do Rio de Janeiro.

Embora o PAE já houvesse sido desenvolvido anteriormente, por meio de telecurso, a versão 2004/5 apresentava características inovadoras que conferiam ao Programa um caráter inédito em termos de complementação de escolaridade na modalidade Educação de Jovens e Adultos. O diferencial da nova proposta, em relação aos cursos de

* Maria AmábIle Mansuttı é pedagoga, integrante da equipe de assessores do CENPEC. Coordenou o projeto de monitoramento e avaliação do programa Aumento de Escolaridade em 2005/2006. LILIANE PETRIS BATISTA é historiadora, mestre pela Faculdade de Educação da USP. No CENPEC, integra a equipe de monitoramento e avaliação do programa Território Escola. suplência oferecidos pelas escolas públicas, estava no fato de o PAE trabalhar em espaços comunitários onde se alocava um público que, por diversas razões, inclusive de segurança, não teria condições de freqüentar escolas das redes públicas de ensino.

Para desenvolver o monitoramento e avaliação do PAE, o CENPEC formulou o Projeto Educação de Base Comunitária para Jovens da Cidade do Rio de Janeiro, que cobriu a implantação do Programa, iniciada em 2004, e seu desenvolvimento até julho de 2005 . 0 projeto aliou acompanhamento diagnóstico e formativo, gerando ações de formação e um plano de monitoramento e avaliação para aferir a efetividade do processo e a eficácia de alguns resultados.

Monitorar e avaliar o desenvolvimento de uma ação educativa inovadora, como o PAE, representou uma oportunidade singular para a produção de análises e reflexões acerca de possibilidades, variações, riscos e acertos na oferta de cursos de complementação de escolaridade e para o avanço de uma discussão nacional sobre a necessidade de garantir a escolaridade fundamental completa para todos os brasileiros.

O PAE atingiu, em março de 2004 , um total de 2.748 estudantes; porém, esse número foi se modificando no decorrer do ano letivo. Assim, em junho, freqüentavam o PAE 4.075 estudantes e, em setembro, 3.833. Em 2005, estavam previstas 156 turmas, totalizando 4.590 estudantes -1.140 para duas organizações parceiras e 1.155 para as outras duas. Em fevereiro de 2005, havia 4.336 estudantes e, em junho, 14.459.

\section{Monitoramento e avaliação no PAE}

Todo projeto que pretenda introduzir novos nexos, objetivos, estratégias e formas organizacionais exige 0 monitoramento de sua implementação e a avaliação do processo e de seus resultados, em função dos objetivos 


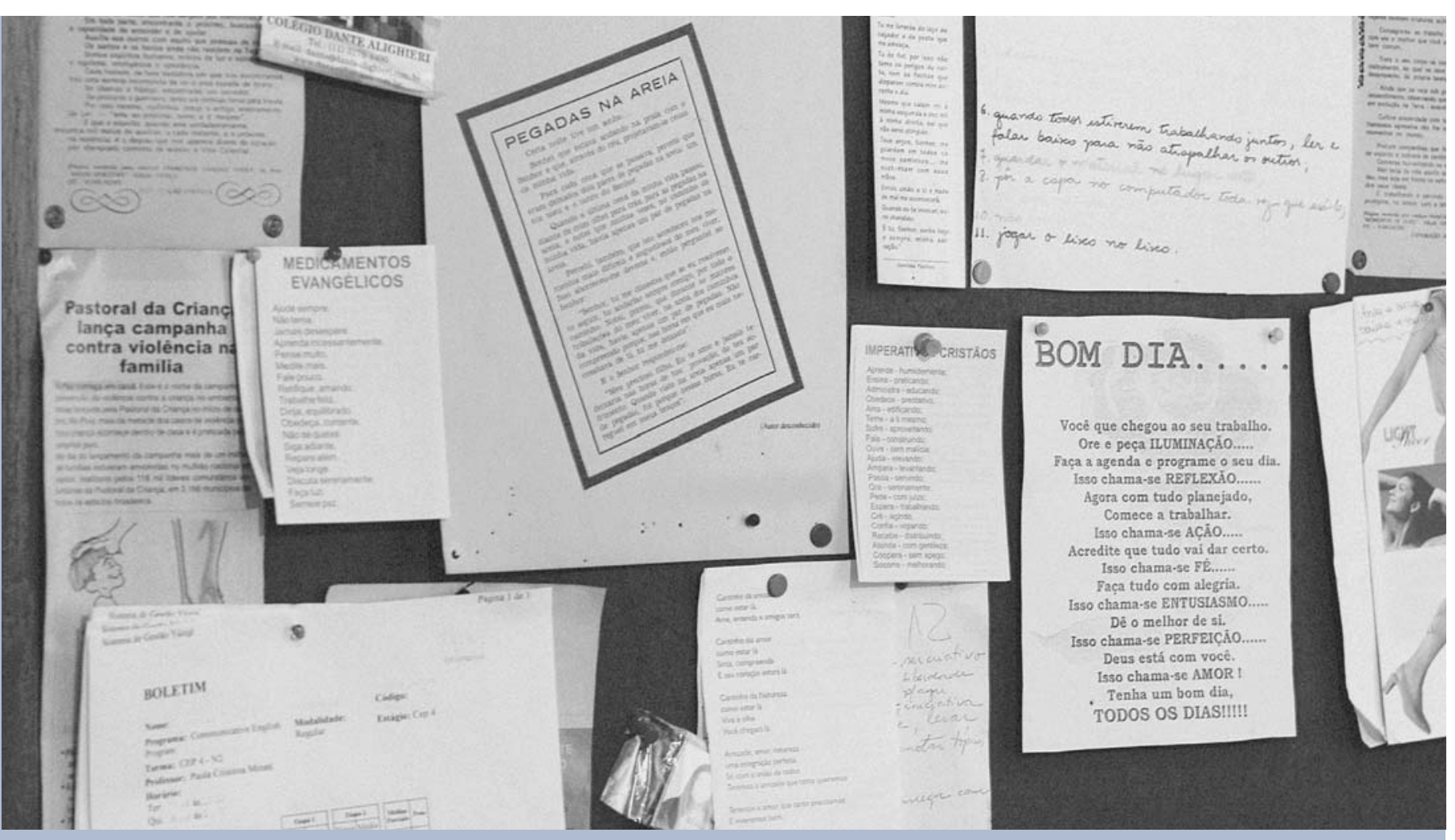

que pretende atingir. Assim, o objetivo principal do plano de monitoramento e avaliação, proposto para o PAE, foi aferir a consistência e aderência do Programa durante o seu desenvolvimento.

O PAE introduzia alguns diferenciais na oferta de escolaridade aos jovens e adultos, sobretudo no que se referia aos aspectos institucionais e pedagógicos. Por isso, a metodologia proposta para desenvolver o monitoramento e a avaliação adotou uma abordagem participativa e formativa, que possibilitou a percepção das transformações ocorridas durante o processo, a ampliação e a consolidação da autonomia e dos conhecimentos produzidos pelos diferentes sujeitos e instituições envolvidas.

Alguns princípios orientaram o plano de monitoramento e avaliação:

- Abrangência, no sentido de contemplar diretrizes estabelecidas no Programa, resultados não previstos e atuação dos segmentos envolvidos, abarcando diferentes percepções e pontos de vista.

- Constituição de um processo formativo que proporcione, aos segmentos participantes, elementos para o aprimoramento de concepções e práticas.

- Garantia da participação das instâncias executoras, de modo a aprimorar a formação de quadros profissionais envolvidos.

- Realismo e exeqüibilidade no tocante às condições técnicas e operacionais das instituições executoras, para que possa se tornar um pilar de sustentação do Programa.

- Valorização das iniciativas da Secretaria Municipal de
Educação do Rio de Janeiro, na área da Educação de Jovens e Adultos, sem colocar em segundo plano nem descuidar das dimensões de proteção e inclusão social, base substantiva do PAE.

A avaliação e o monitoramento desenvolvidos no PAE tinham uma dupla função: sustentar o processo de formação de jovens e adultos, de professores, coordenadores, supervisores e instituições parceiras e, ao mesmo tempo, fazer uma avaliação processual que permitisse identificar obstáculos e elementos facilitadores, assim como o grau de adesão e resistência dos diferentes sujeitos envolvidos. Para tanto, o CENPEC elaborou instrumentos de coleta de dados, que foram submetidos à aprovação das secretarias e das organizações parceiras e possibilitaram a obtenção de informações e a produção de análises para a reorientação de ações e planejamentos.

Os primeiros dados obtidos sobre o Programa, referentes ao levantamento do perfil de estudantes, professores, técnicos e comunidades, foram discutidos em seminário, do qual participaram representantes de todos os segmentos envolvidos no PAE, o que permitiu um momento de reflexão e um mapeamento inicial do projeto, apontando alguns desafios.

Outros dados foram discutidos com os coordenadores das organizações parceiras e com a equipe da SMAS no decorrer do processo.

Os dados quantitativos, coletados em 2004, foram enviados em CD para as equipes das secretarias e das Organizações da Sociedade Civil - OSCs.

A avaliação abarcou diferentes sujeitos, ligados ao Programa, incluindo estudantes e lideranças comunitárias. 


\begin{tabular}{|c|c|c|}
\hline Objetivos & Indicadores & Instrumentos \\
\hline $\begin{array}{l}\text { Avaliar uma alternativa de escolarização para a Edu- } \\
\text { cação de Jovens e Adultos - EJA à medida que: } \\
\text { - propõe uma nova forma de organização de curso; } \\
\text { - faz uso de orientações curriculares, material de } \\
\text { apoio ao estudante e ao professor, elaborados } \\
\text { para atender as especificidades do público-alvo; } \\
\text { - apóia-se na interatividade e na ligação entre esco- } \\
\text { la e comunidade. }\end{array}$ & $\begin{array}{l}\text { Utilização das orientações curricula- } \\
\text { res e materiais de apoio pelos pro- } \\
\text { fessores. } \\
\text { Grau de satisfação dos alunos em } \\
\text { relação ao curso, suas orientações e } \\
\text { seus materiais. } \\
\text { Grau de satisfação dos professores } \\
\text { em relação ao curso, orientações, ma- } \\
\text { teriais e formação. } \\
\text { Relação entre a equipe das organi- } \\
\text { zações parceiras e as lideranças } \\
\text { comunitárias. }\end{array}$ & $\begin{array}{l}\text { Grupos focais com estudantes e pro- } \\
\text { fessores. } \\
\text { Registros dos professores (planeja- } \\
\text { mento, avaliações). } \\
\text { Relatórios das ações de formação } \\
\text { dos professores. } \\
\text { Avaliação dos estudantes e institui- } \\
\text { ções parceiras. } \\
\text { Relatórios de visita aos núcleos. }\end{array}$ \\
\hline $\begin{array}{l}\text { Desenvolver a formação dos estudantes para pro- } \\
\text { mover: } \\
\text { - novos vínculos com a escolarização (freqüência e } \\
\text { interesse); } \\
\text { - uso social dos conhecimentos que adquirem no } \\
\text { PAE; } \\
\text { - continuidade dos estudos. }\end{array}$ & $\begin{array}{l}\text { Número de estudantes inscritos no } \\
\text { Programa (3). } \\
\text { Índices de frequiência e evasão. } \\
\text { Grau de satisfação em relação ao Pro- } \\
\text { grama. } \\
\text { Índices de aprovação por unidades } \\
\text { de progressão. }\end{array}$ & $\begin{array}{l}\text { Ficha de inscrição. } \\
\text { Cadastro e perfil dos estudantes. } \\
\text { Planilha mensal de freqüência/eva- } \\
\text { são. Resultados de avaliação por UP. } \\
\text { Grupos focais. } \\
\text { Relatórios de visitas aos locais dos } \\
\text { cursos - CENPEC. }\end{array}$ \\
\hline $\begin{array}{l}\text { Promover e apoiar a atuação do professor para: } \\
\text { - aprimorar seus conhecimentos e vínculos, a fim de } \\
\text { que exerça a docência e obtenha informações so- } \\
\text { bre as características particulares dos estudantes; } \\
\text { - despertar seu interesse em discutir critérios de se- } \\
\text { leção e organização de conteúdos curriculares do } \\
\text { PAE; } \\
\text { - subsidiar o trabalho docente na construção de um } \\
\text { curso que atenda às necessidades do público- } \\
\text { alvo. }\end{array}$ & $\begin{array}{l}\text { Número de professores que participa- } \\
\text { ram do Programa (assiduidade, auto- } \\
\text { nomia, abandono). } \\
\text { Pautas dos encontros de formação. } \\
\text { Grau de entendimento, envolvimento } \\
\text { e satisfação em relação ao Programa. } \\
\text { Presença dos elementos da realida- } \\
\text { de local nas práticas e nos conteúdos } \\
\text { desenvolvidos na sala de aula. } \\
\text { Resultados obtidos nas avaliações } \\
\text { da aprendizagem dos estudantes. }\end{array}$ & $\begin{array}{l}\text { Planilhas de freqüência. } \\
\text { Cadastro e perfil dos professores. } \\
\text { Grupos focais com estudantes, } \\
\text { professores, supervisores e coor- } \\
\text { denadores. } \\
\text { Relatórios da equipe de formação. } \\
\text { Observação da sala de aula. }\end{array}$ \\
\hline $\begin{array}{l}\text { Apoiar a atuação dos coordenadores, assistentes } \\
\text { de coordenação e supervisores das OSCs na: } \\
\text { - organização de uma dinâmica de trabalho que } \\
\text { garanta planejamento, periodicidade das ações, } \\
\text { participação, registro das tarefas, avaliação e in- } \\
\text { tervenções necessárias; } \\
\text { - assessoria aos professores nos aspectos pedagó- } \\
\text { gicos. }\end{array}$ & $\begin{array}{l}\text { Gestão do Programa: circulação de } \\
\text { informações entre as diferentes ins- } \\
\text { tâncias envolvidas. } \\
\text { Periodicidade do contato com profes- } \\
\text { sores e locais dos cursos. } \\
\text { Formação dos professores: carga ho- } \\
\text { rária, periodicidade, pautas. }\end{array}$ & $\begin{array}{l}\text { Entrevistas com supervisores e co- } \\
\text { ordenadores. } \\
\text { Análise documental. } \\
\text { Visitas do CENPEC aos locais dos } \\
\text { cursos. } \\
\text { Grupo focal com coordenadores. }\end{array}$ \\
\hline $\begin{array}{l}\text { Contribuir para a viabilização de parcerias entre } \\
\text { instâncias de governo (SMDS e SME), organizações } \\
\text { da sociedade civil e associações de moradores, na } \\
\text { implementação de ação política que visa à escola- } \\
\text { rização de jovens e adultos, de forma que: } \\
\text { - possibilite experiência de gestão compartilhada; } \\
\text { - garanta condições técnico-pedagógicas de realiza- } \\
\text { ção do Programa; } \\
\text { - proporcione troca de experiências e ampliação de } \\
\text { conhecimentos; } \\
\text { - assegure documentação, análise e avaliação da } \\
\text { experiência nos aspectos institucionais e peda- } \\
\text { gógicos. }\end{array}$ & $\begin{array}{l}\text { Disponibilização de materiais. } \\
\text { Circulação de informações. } \\
\text { Periodicidade das reuniões e conta- } \\
\text { tos entre os parceiros. } \\
\text { Estabelecimento de acordos entre } \\
\text { os parceiros. } \\
\text { Intervenções realizadas. }\end{array}$ & $\begin{array}{l}\text { Avaliação do Programa realizada } \\
\text { pelos parceiros. } \\
\text { Avaliação do Programa feita pe- } \\
\text { los diferentes atores beneficiados } \\
\text { (alunos e comunidades). } \\
\text { Entrevistas individuais. }\end{array}$ \\
\hline
\end{tabular}


As análises produzidas focalizaram as seguintes dimensões:

- Estudantes - interesse pelo Programa, freqüência, participação, representações sobre a escolaridade; processos de aprendizagem; relações com a comunidade.

- Professores - participação, atuação pedagógica adequada à realidade do Programa, representações sobre a escolarização de jovens e adultos.

- OSCs - implementação e execução do Programa.

- Técnicos do PEJ (SME) - diretrizes pedagógicas do PAE.

- Técnicos da SMAS - apoio logístico e acompanhamento do Programa em todas as dimensões (estrutural, organizacional, pedagógica).

\section{0 processo e os indicadores de avaliação}

De modo geral, as organizações dão muita importância ao planejamento da ação e reservam um lugar secundário para a avaliação, interpretando-a apenas como justificativa de uma ação ou como procedimento de prestação de contas. Com o plano de monitoramento e avaliação proposto, o CENPEC procurou tratar a avaliação como um processo que permitisse aprimorar as ações e manter uma discussão aberta no que tange aos propósitos, processos e resultados do PAE.

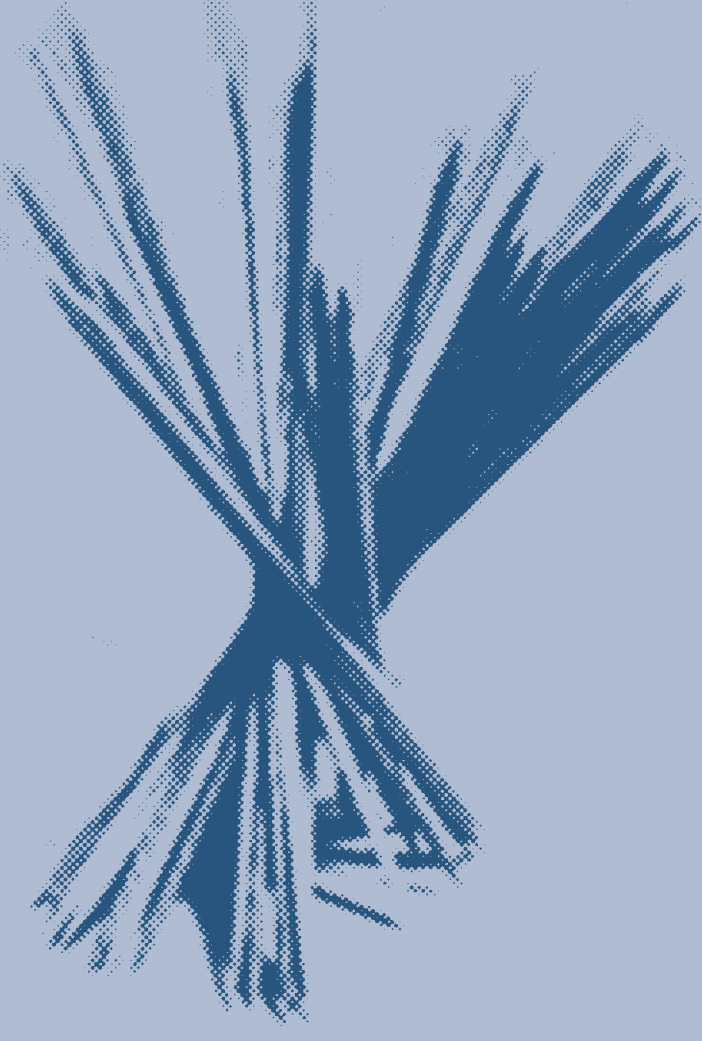

Para tanto, foi necessário definir objetivos relacionados às dimensões focalizadas pelo PAE e, para cada um deles, propor um conjunto de indicadores e de instrumentos de coleta de informações que garantisse tanto uma visão de aspectos quantitativos, quanto de qualitativos.

Foram utilizadas as seguintes estratégias no levantamento de dados: entrevistas individuais, grupos focais, mapas de desempenho dos estudantes nas avaliações periódicas e finais, questionários estruturados, roteiro de observação local, fichas quantitativas (matrícula, freqüência mensal, evasão).

O processo de monitoramento foi retardado pelas dificuldades iniciais para se formular um planejamento conjunto entre CENPEC, SMAS e SME e definir as informações que seriam solicitadas às organizações parceiras, o que provocou uma sobrecarga de trabalho para os coordenadores e os supervisores.

Os indicadores foram definidos a partir de parâmetros que orientam o Programa Aumento de Escolaridade, e dos objetivos e estratégias indicados. Eles englobam três categorias:

- realidade educativa (estrutura, organização e gestão do Programa; currículo, sistema de avaliação e práticas da sala de aula);

- sucesso/fracasso escolar (matrícula, evasão, freqüência, resultados da aprendizagem, certificação no EF);

- caminho multissetorial: educação e proteção social, opção básica desenhada neste Programa.

\section{Reflexões e indicações sobre a experiência}

O PAE apresenta-se como um modelo de escolarização para EJA, recomendável para ser implantado em regiões vulneráveis devido à pobreza e riscos sociais, desde que associe efetivamente ações de escolarização e proteção social como opção básica da proposta.

Em futuras implantações, é preciso considerar os riscos da descontinuidade. Devido ao alto grau de vulnerabilidade a que está sujeito o público-alvo deste Programa, depois de ingressarem no PAE, dificilmente os estudantes terão condições de organizar a vida pessoal e migrar para as escolas integradas aos sistemas de ensino. Assim, caso não possam continuar no Programa até concluírem o curso, esses grupos certamente estarão fadados a se deparar com um novo fracasso, na tentativa de completarem o ensino fundamental.

A experiência do PAE mostrou que o sucesso de sua 
implantação apóia-se nos estreitos vínculos estabelecidos entre as instituições gestoras e as comunidades e lideranças locais. Por isso, a gestão precisa considerar e investir em estratégias de articulação entre formuladores, gestores e beneficiários do Programa, para promover a escolarização e a proteção social.

$\mathrm{Na}$ busca de aprimoramento do modelo organizacional do PAE, será necessário se pensar em mudanças que considerem fatores apresentados nesta análise, sobretudo no que se refere à dramática realidade da suspensão de aulas, propondo uma organização do tempo mais flexível e uma proposta curricular mais orgânica. Assumir essa perspectiva realista não significa reduzir as expectativas em relação à qualidade, mas ter uma visão estratégica coerente com a realidade vivida nesta experiência do PAE.

Pode-se pensar num curso que inclua momentos de estudo presenciais e não-presenciais, estruturado em módulos, oficinas e projetos:

- Módulos organizados a partir dos conteúdos fundamentais das áreas do currículo, com tempo delimitado e indicação de expectativas de aprendizagem previstas ao término de cada módulo. Atividade presencial desenvolvida três vezes por semana.

- Oficinas culturais direcionadas para a ampliação dos conhecimentos e para promover a integração e o convívio dos jovens e adultos. Poderá abarcar eixos como:

- a comunicação e a compreensão de diferentes tipos de linguagens - verbal, textual, corporal, fotográfica etc.;

- a convivência social - ética, valores, direitos, trânsito nos espaços públicos, solução de conflitos, erradicação de preconceitos culturais e discriminações, conhecimento ajustado de si mesmo, autoconfiança etc.;

- o domínio de recursos tecnológicos - informática, tecnologias da informação e da comunicação: TV, vídeo etc.;

- o senso estético e a valorização das diferentes formas de arte - música, cinema, teatro, artes plásticas etc. Atividade presencial semanal ou quinzenal.

- Projetos desenvolvidos com a perspectiva de aplicar, de forma integrada, os conhecimentos estudados nos módulos e nas oficinas, para investigar problemas ou assuntos de interesse da comunidade local e apontar alternativas para minimizá-los.
Muitas questões marcaram o desenvolvimento do PAE; uma das mais relevantes diz respeito à composição de uma parceria inédita, que reuniu a Secretaria de Educação e a Secretaria da Assistência Social; organizações da sociedade civil, como gestoras da ação, e, ainda, uma terceira instituição encarregada de seu monitoramento e avaliação.

Com essa composição, a experiência do PAE foi construída baseada em um modelo de gestão articulada que demandou um grau de envolvimento considerável de todos e pressupôs que se criasse um fluxo de informação e divulgação eficiente. Exigiu abertura e disposição para se compreender, de modo consensual, a natureza do Programa e a necessidade de flexibilidade para a tomada de decisões, possibilitando o surgimento de novas idéias e a formulação coletiva de processos e estratégias mais compatíveis com a natureza da ação.

A familiaridade e a proximidade, estabelecidas entre a equipe de avaliação e o grupo executivo, reverteram 0 estranhamento inicial e permitiram ao CENPEC oferecer algumas contribuições para a formação dos professores, a adequação do currículo e a avaliação da aprendizagem, à luz das análises e avaliações produzidas no processo de desenvolvimento do PAE.

A experiência de escolarização do PAE é singular e complexa; por isso, exige o compartilhamento de conhecimentos, experiências e visões de diferentes instituições para que se desenvolva de modo satisfatório. Uma parceria, como a estabelecida neste Programa, pressupõe uma nova cultura de gestão compartilhada, que implica possibilidades de diálogo em tempo real; comunicação por escrito, por meio de mensagens curtas e objetivas; e coletivizar o processo de tomada de decisões.

No PAE, nem sempre foi possível vivenciar os processos de uma gestão compartilhada como era o desejo de todos, porém, há saldos positivos nessa experiência. O papel desempenhado pela coordenação do Programa, sediada na SMAS, foi fundamental para a efetivação das condições e o apoio administrativo que ofereceu às organizações sociais.

Em ações nas quais estejam envolvidas duas ou mais secretarias, aprendemos que é fundamental haver uma divisão clara de atribuições e responsabilidades, com momentos de discussão e reflexão sobre essa ação conjunta e uma instância que faça a intermediação dessa relação e contribua para a resolução e a superação de possíveis obstáculos ou dificuldades. 


\section{Em ações nas quais estejam}

\section{envolvidas duas ou mais}

secretarias, aprendemos que

\section{é fundamental haver uma}

divisão clara de atribuições

e responsabilidades, com

momentos de discussão e

reflexão sobre essa acão

conjunta e uma instância

que faça a intermediação

dessa relação e contribua

para a resolução e a

superação de possíveis

obstáculos ou dificuldades.

Também as quatro organizações sociais parceiras tiveram uma atuação destacada e procuraram trabalhar de modo integrado, apoiando-se mutuamente e trocando experiências. A constituição de fortes vínculos de articulação entre as equipes da SMAS, das instituições sociais e as comunidades atendidas foi, e continua sendo, fundamental para a efetivação do programa e para garantir, de algum modo, a preservação física dos professores e supervisores que entram nas comunidades.

Os líderes comunitários reconhecem a importância dessa parceria e sabem que são figuras-chave. Segundo sua avaliação, a implantação do PAE tem contribuído para que a associação de moradores tenha um reconhecimento maior pela comunidade. Destaca-se, ainda, o fato de que as verbas destinadas, pelo Programa, às associações permitem que elas melhorem sua infra-estrutura.

Ainda será preciso que as organizações públicas e privadas incorporem, em suas práticas, a produção de investigações e conhecimentos sobre determinadas questões e contribuam para fazer avançar os estudos sobre 0 ensino e a aprendizagem de jovens e adultos, que ainda são bastante incipientes na área da pesquisa educacional. Uma dessas questões diz respeito à evasão.

Também é interessante que se estude mais o movimento da freqüência dos estudantes, que foi bastante irregular no PAE, bem como as questões relacionadas diretamente com a aprendizagem. A escolarização proposta no PAE é uma experiência rica em termos de informações e variáveis para alimentar essas investigações.

Diante desses fatos, é importante se refletir o quanto as experiências alternativas de escolarização, como o PAE, precisam criar condições para que as práticas pedagógicas se tornem mais produtivas, agregando estudos, monitoramento e avaliação das práticas habitualmente utilizadas em sala de aula e estimulando a formulação de outras.

A experiência PAE ainda revelou que a associação entre escolaridade e proteção social é um ponto forte, embora de difícil articulação. Por exemplo, há muitas mulheres que desejam estudar e não têm com quem deixar seus filhos; ou os casos de violência contra as mulheres estudantes relatados nos grupos focais; e, ainda, a necessidade de se desenvolver ações, como a campanha de regularização de documentos pessoais, a fábrica de cartões postais, idéias nascidas no PAE, que não foram levadas adiante.

Um programa que contempla uma região de alto risco social não pode deixar de atuar na área da proteção. As equipes dos órgãos de Assistência Social e as organizações parceiras devem ser mais propositivas nesse sentido, pois a realidade das comunidades mais vulneráveis enseja ações de apoio psicossocial para que possam lidar com os problemas que emergem tanto para os estudantes quanto para os professores.

Cabe pensar ainda nas possibilidades de aprendizado e uso da tecnologia digital. Em vários momentos, os estudantes do PAE afirmaram que gostariam de aprender informática e, certamente, 0 acesso ao computador e à Internet poderia facilitar o aprendizado on line, evitando-se a imposição de freqüência diária regular, que exige tempo e disposição nem sempre disponíveis naquelas condições.

Por fim, seria recomendável e necessário intensificar a vertente cultural de programas de escolarização de jovens e adultos, casando educação formal e outros processos de aprendizagem que ajudem a criar um repertório ampliado, facilitando a apreensão dos conteúdos curriculares.

\section{Notas}

1 Os dados aqui apresentados constituem parte do relatório avaliativo de dezembro de 2005, elaborado pelo CENPEC - Centro de Estudos e Pesquisas em Educação, Cultura e Ação Comunitária.

2 Indicadores de avaliação são sinalizadores de processo e de resultados relativos a uma dada ação planejada. São como um termômetro criado para orientar e aferir a observação, o registro e a avaliação de planos, programas, projetos e ações pretendidas. 